\title{
PENGEMBANGAN LKPD BERBASIS DISCOVERY LEARNING BERBANTUAN SOFTWARE TRACKER UNTUK MENINGKATKAN PEMAHAMAN KONSEP PESERTA DIDIK KELAS X MATERI GERAK LURUS
}

\author{
Nova Anjarwati ${ }^{1}$, Patricia H.M. Lubis ${ }^{2}$, Sugiarti $^{3}$ \\ Profram Studi Pendidikan Fisika, FKIP, Uniersitas PGRI Palembang \\ Email: novaanjarwati17@gmail.com
}

Diterima: 10 Juli 2021. Direvisi: 18 Agustus 2021. Disetujui: 30 Agustus 2021.

\begin{abstract}
Abstrak
Penelitian pengembangan lembar kerja peserta didik (LKPD) berbasis discovery learning berbantuan software tracker. Penelitian ini bertujuan untuk menghasilkan produk LKPD berbasis discovery learning berbantuan software tracker yang valid, praktis, dan memiliki efek potensial terhadap pemahaman konsep peserta didik. Metode Penelitian yang digunakan dalam penelitian ini adalah penelitian dan pengembangan (research \& development), dengan menggunakan model pengembangan Rowntree yang terdiri dari tiga tahap, yaitu : 1) perencanaan, 2) pengembangan, dan 3) evaluasi, dengan dimodifikasi evaluasi formatif Tessmer (self evaluation, expert review, one to one, small group, dan field test). Subjek dalam penelitian ini yaitu peserta didik kelas X SMA Sriguna Palembang. Pengumpulan data dilakukan dengan cara walkthrough, angket, dan tes pemahaman konsep. Berdasarkan analisis data ini dinyatakan valid, praktis, dan memiliki efek potensial terhadap pemahaman konsep peserta didik. Adapun hasil yang diperoleh 1) Tahap expert review memperoleh dengan nilai rata-rata dari ketiga validator sebesar $82 \%$ dikategorikan sangat valid; 2) Tahap one to one memperoleh dengan nilai rata-rata sebesar $91 \%$ dikategorikan sangat praktis; 3) Tahap small group memperoleh dengan nilai rata-rata sebesar $88 \%$ dikategorikan sangat praktis; 4) Tahap field test memperoleh dengan nilai rata-rata pre test sebesar 35,29 sedangkan post test sebesar 78,52 dengan nilai rata-rata $N$-Gain sebesar 0,72 dengan dikategorikan tinggi.
\end{abstract}

Kata Kunci: LKPD, Discovery Learning, Software Tracker, Pemahaman Konsep.

\begin{abstract}
Research on the development of student worksheets (LKPD) based on discovery learning assisted by a software tracker. This study aims to produce LKPD products based on discovery learning assisted by software trackers that are valid, practical, and have a potential effect on students' understanding of concepts. The research method used in this research is research and development (research \& development), by using the Rowntree development model which consists of three stages, namely: 1) planning, 2) development, and 3) evaluation, modified by Tessmer's formative evaluation (self evaluation, expert review, one to one, small group, and field test). The subjects in this study were students of class X SMA Sriguna Palembang. Data was collected by means of walkthroughs, questionnaires, and concept
\end{abstract}


Anjarwati., Lubis., Sugiarti. - Pengembangan LKPD Berbasis Discovery...

understanding tests. Based on this data analysis, it is declared valid, practical, and has a potential effect on students' understanding of concepts. The results obtained 1) The expert review stage obtained with an average value of the three validators of $82 \%$ categorized as very valid; 2) The one to one stage is obtained with an average value of $91 \%$ which is categorized as very practical; 3) The small group stage obtained an average score of $88 \%$ which was categorized as very practical; 4) The field test stage is obtained with an average pre-test value of 35.29 while the post-test is 78.52 with an average $N$-Gain value of 0.72 which is categorized as high.

Keywords: LKPD, Discovery learning, Software Tracker, Conceptual Understanding.

\section{PENDAHULUAN}

Perkembangan ilmu pengetahuan dan teknologi di tengah era revolusi industri 4.0 menjadi tantangan generasi muda dan juga di dunia Pendidikan di Indonesia. Di dalam proses pendidikan tidak pernah terlepas dari kegiatan belajar dan proses pembelajaran. Pembelajaran adalah suatu usaha sadar dari seorang pendidik dalam rangka untuk mencapai tujuan yang diinginkan agar bisa membelajarkan peserta didiknya dan mengarahkan interaksi peserta didik dengan sumber belajar lainnya (Pasaribu, \& Saparini, 2017). Pembelajaran yang tepat diharapkan dapat membantu peserta didik dalam memahami materi fisika.

Mata pelajaran fisika menjelaskan seluruh fenomena yang terjadi di alam ini, sehingga masalah-masalah yang berhubungan dengan fisika kerap kita jumpai dikehidupan sehari-hari, Pembelajaran fisika dengan memanfaatkan kejadian fisika memungkinkan peneliti atau peserta didik untuk menerapkan konsep fisika (Aththibby, \& Salim, 2015).

Berdasarkan hasil wawancara yang dilakukan peneliti di SMA Sriguna Palembang permasalahan yang dihadapai yaitu; 1). Peserta didik kurang termotivasi untuk belajar karena pembelajaran masih bersifat teori; 2). Media pembelajaran yang digunakan oleh pendidik belum mendukung tercapainya suatu tujuan pembelajaran; 3). Kurangnya aplikasi materi pembelajaran pada kehidupan sehari-hari, sehingga peserta didik bosan dalam mengikuti proses pembelajaran fisika; 4). Pendidik mengajarkan peserta didik biasanya menggunakan sesuatu yang abstrak dengan metode ceramah. Untuk mengatasi permasalahan diatas 
Anjarwati., Lubis., Sugiarti. - Pengembangan LKPD Berbasis Discovery...

pendidik dapat membimbing peserta didik dan dapat menentukan keberhasilan peserta didik dalam proses pembelajaran dengan menggunakan LKPD hal ini sejalan dengan Firdaus dan Wilujeng (2018) LKPD adalah lembar kegiatan proses pembelajaran untuk menemukan konsep IPA baik melalui materi, demonstrasi dan penyeledikan disertai petunjuk dan prosedur kerja untuk melatih keterampilan berpikir dan proses IPA yang sesuai dengan indikator pembelajaran yang dicapai.

solusi peneliti dalam penelitian ini yaitu menggunakan media LKPD berbantuan software tracker. Software tracker adalah software yang digunakan untuk menganalisis video khusus pembelajaran fisika pada materi kinematika dan dinamika (Hasanah et al., 2019). Menurut Hardi, Wahyono, \& Saehana (2019) Tracker merupakan program yang dapat digunakan untuk menganalisis berbagai video berkaitan dengan topik kinematika gerak lurus dan spektrum cahaya dan fitur yang dimiliki oleh tracker antara lain pelacakan objek dengan overlay posisi, kecepatan,percepatan, grafik, beberapa kerangka acuan, titik kalibrasi dan profil garis. Tracker merupakan perangkat lunak software untuk menganalisis gerak suatu benda melalui video berkaitan dengan materi gerak lurus, sehingga dapat mengghasilkan parameter perubahan posisi, parameter kecepatan, percepatan, energi kinetik, energi potensial dan parameter lainnya yang memiliki objek yang bergerak (Nugraha et al., 2017).

Untuk meningkatkan pemahaman konsep peserta didik maka perlu diberikan proses pembelajaran dengan menggunakan pendekatan atau model pembelajaran. Model pembelajaran adalah dapat dijadikan pola pilihan, artinya para guru boleh memilih model pembelajaran yang sesuai dan efisien untuk mencapai tujuan pembelajaran. untuk meningkatkan pemahaman konsep peserta didik yaitu model pembelajaran yang sesuai dengan permasalahan pelajaran fisika yaitu discovery learning (Esminarto, et al., 2016). Discovery learning adalah pembelajaran untuk menemukan konsep, memahami makna dan menghubungkan 
Anjarwati., Lubis., Sugiarti. - Pengembangan LKPD Berbasis Discovery...

pembelajaran yang dilakakukan oleh peserta didik (Brigenta et al., 2017).

Berdasarkan uraian dan permasalahan di atas, adapun tujuan dari penelitian ini untuk mengembangkan LKPD berbasis discovery learning berbantuan software tracker yang valid, praktis dan efektif bagi peserta didik melalui pengembangan LKPD berbasis discovery learning berbantuan software tracker ini peneliti berharap peserta didik dapat termotivasi dan lebih aktif dalam mengikuti proses pembelajaran fisika agar kemampuan peserta didik dalam memahami konsep fisika dapat meningkat.

\section{METODE}

Metode Penelitian yang digunakan dalam penelitian ini adalah penelitian dan pengembangan (research \& development) untuk menghasilkan produk dan menguji keefektifan produk tersebut (Sugiyono, 2013). Produk yang dikembangkan adalah LKPD berbasis discovery learning berbantuan software tracker untuk meningkatkan pemahaman konsep peserta didik kelas X di SMA Sriguna Palembang.
Model pengembangan yang digunakan yaitu Rowntree yang terdiri dari tiga tahap yaitu tahap perencanaan, tahap pengembangan, dan tahap evaluasi (Badiro,Syuhendri, \& Fathurohman, 2019). Pada tahap evaluasi dimodifikasi dengan model evaluasi formatif Tessmer (1998) berdasarkan karakteristik secara umum terdapat lima jenis yaitu: evaluasi diri (self evaluation), tinjauan ahli (expert review), evaluasi satu-satu (one to one), kelompok kecil (small group), dan uji lapangan (field test).

Teknik analisis data yang digunakan adalah analisi data walkthrough yang merupakan validasi data yang digunakan untuk mengevaluasi data dengan menggunakan lembar angket validasi yang diberikan kepada ahli berupa skala likert yang akan dilakukan perhitungan skor dengan mengkategorikan nilai validasi (Apriyani, Sumarni, \& Rukiyah, 2018). Selanjutnya, teknik analisis data one to one dan small group yang digunakan untuk menguji kepraktisan suatu produk LKPD yang dikembangkan. Data yang diperoleh 
Anjarwati., Lubis., Sugiarti. - Pengembangan LKPD Berbasis Discovery...

menggunakan angket tanggapan pembelajaran berlangsung; (3) peserta didik dalam bentuk skala Kurangnya aplikasi materi likert. Teknik analisis data field test pembelajaran pada kehidupan seharidigunakan untuk mengetahui hari, sehingga peserta didik bosan pemahaman kosep peserta didik. dalam mengikuti proses pembelajaran Peningkatan pemahaman konsep fisika; (4) Pendidik mengajarkan peserta didik dilihat dari nilai $\mathrm{N}$-gain dari hasil pretest dan posttest.

\section{HASIL DAN PEMBAHASAN}

Hasil yang diperoleh dalam penelitian ini yaitu LKPD berbasis discovery learning berbantuan software tracker. Tahap awal dalam penelitian ini adalah perencanaan. Tahap ini dilakukan dengan tiga langkah yaitu analisis kebutuhan LKPD berdasarkan Wawancara dengan guru dan peserta didik untuk mendafatkan informasi mengenai bahan ajar yang digunakan dalam proses belajar mengajar di sekolah tersebut. Adapun hasil wawancara dengan guru dan peserta didik yaitu (1) Peserta didik kurang termotivasi untuk belajar karena pembelajaran masih bersifat teori; (2) Media pembelajaran yang digunakan oleh pendidik belum mendukung tercapainya suatu tujuan pembelajaran, pada saat proses peserta didik biasanya menggunakan sesuatu yang abstrak dengan metode ceramah. Pada tahap analisis materi, Materi yang dianggap sulit untuk dipahami secara mandiri oleh peserta didik adalah materi gerak lurus. Maka, dengan demikian peneliti mengembagkan LKPD materi gerak lurus. Terdapat fakta, konsep, prinsip dan prosedur dari materi gerak lurus. Selanjutnya, pada tahap analisis tujuan pembelajaran berdasarkan kurikulum peneliti menganalisis Kompetensi dasar, indikator yang sesuai dengan silabus dan kurikulum yang berlaku disekolah.

Tahap pengembangan terdiri dari tiga langkah yaitu menetukan pengembangan topik, penyusunan draf, dan produksi prototype. Pada tahap pengembangan topik dan mengumpulkan sumber yang akan digunakan dalam proses pembuatan LKPD. Peneliti menggunakan dua buku dan sumber dari internet yang 
Anjarwati., Lubis., Sugiarti. - Pengembangan LKPD Berbasis Discovery...

dijadikan sebagai acuan dalam pembuatan LKPD. Penelitian selanjutnya melakukan penyusunan draf LKPD untuk mempermudah dalam pelaksanaan pengembangan LKPD.

Penyusunan draf dilakukan dengan menentukan komponen-komponen yang akan ditulis di prototype 1. Selanjutnya, peneliti melakukan produksi prototype 1 LKPD berbasis discovery learning berbantuan software tracker yang disesuaikan dengan hasil pengembangan topik dan penyusunan draf LKDP. Tampilan LKPD Berbasasis Discovery Learning dapat dilihat pada Gambar 1.
Tahap evaluasi dimulai dengan self evaluation. Tahap ini dilakukan penilaian sendiri serta dikonsultasikan kepada dosen pembimbing. Hal ini bertujuan untuk memperbaiki kekurangan pada LKPD yang dikembangkan. Adapun hasil self evaluation yaitu (1) Buat LKPD menjadi 2 pertemuan; (2) Tambahkan kunci jawaban pada LKPD; (3) Tambahkan gambar agar lebih menarik pada LKPD; (4) Perbaiki Materi GLBB dan tambahkan lagi penjelasan materi GLBB pada LKPD; (5) ACC Silahkan Validasi.
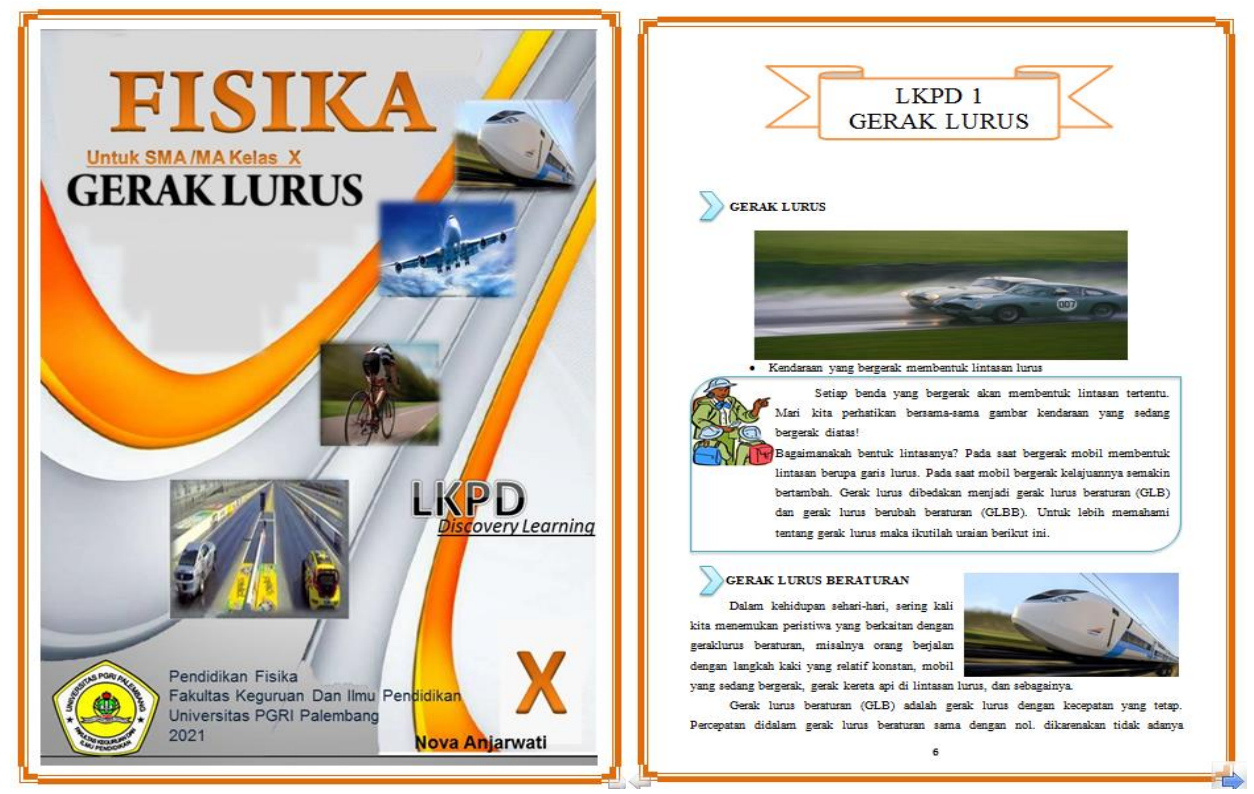

Gambar 1. Tampilan LKPD Berbasasis Discovery Learning 
Anjarwati., Lubis., Sugiarti. - Pengembangan LKPD Berbasis Discovery...

Pada tahap expert review bertujuan untuk mendapatkan LKPD berbasis discovery learning berbantuan software tracker yang valid. Validasi LKPD ini dinilai oleh ketiga validator pada tiga aspek yaitu aspek materi, aspek desain pembelajaran, aspek bahasa.

Tahap ini dilakukan dengan menggunakan skala likert. Hasil ratarata tersebut dapat dilihat pada Gambar 2.

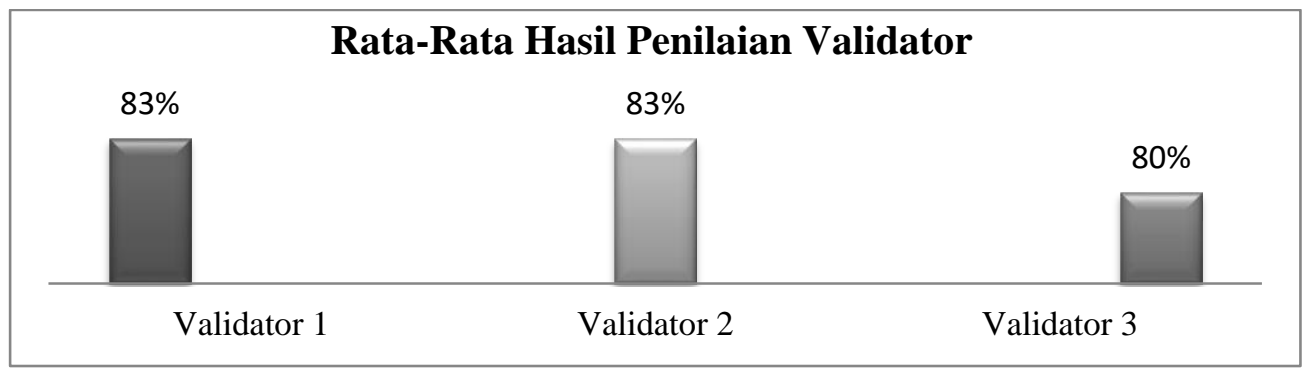

Gambar 2. Grafik Rekapitulasi Hasil Penilaian Ketiga Validator

Berdasarkan Gambar 2, diperoleh rata-rata hasil penilaian dari ketiga validator sebesar $82 \%$ dan dikategorikan sangat valid. Walaupun hasil prototype 1 dinyatakan sangat valid namun para ahli validator tetap memberikan komentar dan saran untuk memperbaiki LKPD berbasis LKPD berbasis discovery learning berbantuan software tracker yang dikembangkan.

Tahap berikutnya adalah one to one evaluation. Tahapan ini bertujuan untuk mengetahui kepraktisan LKPD berbasis discovery learning berbantuan software tracker yang telah dibuat oleh peneliti. Tahap ini melibatkan tiga peserta didik dan mereka secara bersamaan menggunakan prototype 1. Peserta didik diminta untuk mengisi lembar angket tanggapan mereka terhadap prototype 1 yang telah digunakan.

Adapun hasil rata-rata tanggapan peserta didik terhadap LKPD berbasis discovery learning berbantuan software tracker pada tahap one to one pada Gambar 3.

Berdasarkan Gambar 3 diperoleh rata-rata tanggapan peserta didik terhadap LKPD berbasis discovery learning berbantuan software tracker sebesar $91 \%$ sehingga dapat disimpulkan bahwa prototype 1 
Anjarwati., Lubis., Sugiarti. - Pengembangan LKPD Berbasis Discovery...

dikategorikan sangat praktis. Namun selain hasil penilaian burapa angka peserta didik juga memberikan saran dan komentar pada prototype 1 yang akan dikembangkan.

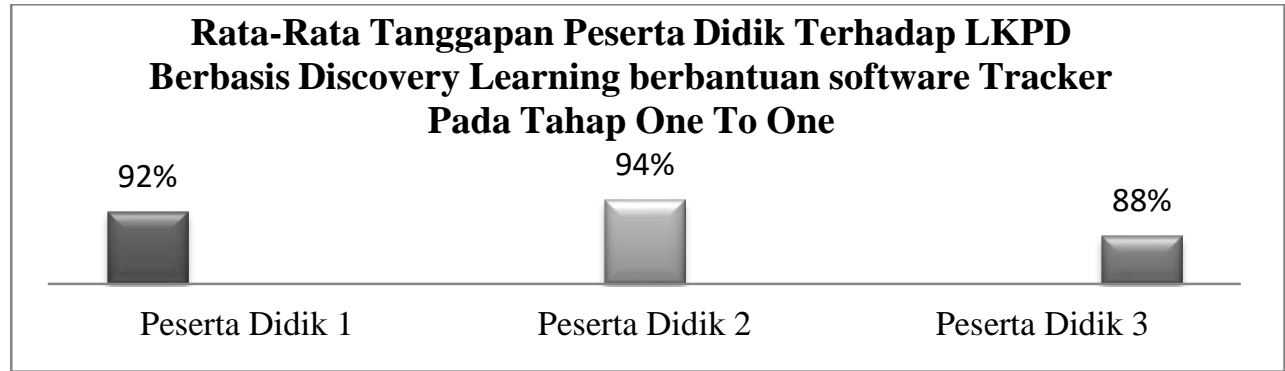

Gambar 3. Grafik Rata-Rata Tanggapan Peserta Didik Tahap One To One

Pada tahap small group evaluation hampir sama dengan tahap one to one, bedanya peneliti mengujicobakan prototype 2 kepada sepuluh orang peserta didik untuk mengisi angket tanggapan terhadap prototyppe 2 yang telah digunakan. Berikut hasil tanggapan peserta didik tahap small group pada Gambar 4. rata-rata tanggapan peserta didik terhadap penggunaan prototype 2 adalah sebesar $88 \%$ sehingga dikategorikan sangat praktis. Selain mengisi angket pesertda didik juga diminta untuk memberikan komentar dan saran mengenai LKPD berbasis discovery learning berbantuan software tracker yang dikembangkan.

Berdasarkan gambar 4 diperoleh

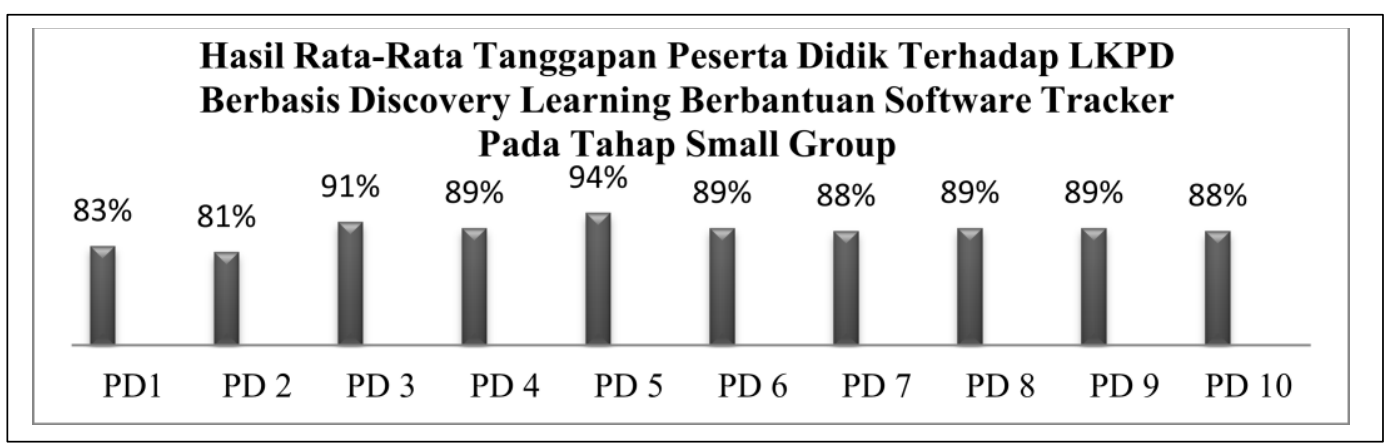

Gambar 4. Grafik Rata-Rata Tanggapan Peserta Didik Tahap Small Group 
Anjarwati., Lubis., Sugiarti. - Pengembangan LKPD Berbasis Discovery...

Tahap field test prototype 3 peserta didik diperoleh dari hasil diujicobakan dengan subjek penelitian pretest dan posttest yang telah mereka berjumlah 34 orang peserta didik kerjakan. Hasil perhitungan skor kelas X IPA 1 SMA Sriguna pretest dan posttest pemahaman Palembang. Tahap ini bertujuan untuk konsep menggunakan standar $N$-gain mengetahui efek potensial terhadap dapat dilihat pada Tabel 1. peningkatan pemahaman konsep

Tabel 1 . Hasil Standar N-gain Peningkatan Pemahaman Konsep

\begin{tabular}{cccccc}
\hline $\begin{array}{c}\text { Nilai } \\
\text { rata-rata } \\
\text { pretest }\end{array}$ & $\begin{array}{c}\text { Nilai rata- } \\
\text { rata } \\
\text { posttest }\end{array}$ & Batasan $N$-gain & $\begin{array}{c}\text { Jumlah } \\
\text { Peserta } \\
\text { didik }\end{array}$ & Presentase & Kategori \\
\hline \multirow{3}{*}{35,29} & 78,52 & $\begin{array}{c}N \text {-gain }>0,70 \\
0,30 \leq N \text {-gain } \leq 0,70\end{array}$ & 21 & $62 \%$ & Tinggi \\
& & $N$-gain $<0,30$ & 0 & $38 \%$ & Sedang \\
& & & & & Rendah \\
\hline
\end{tabular}

Pada Tabel 1 diperoleh hasil $N$ gain peserta didik menunjukkan presentase tahap field test yaitu $62 \%$ peserta didik termasuk dalam kategori $N$-gain tinggi, dan $38 \%$ peserta didik termasuk dalam kategori sedang. Jika ditinjau dari rerata dari hasil $N$-gain pada pretest dan posttest memperoleh rata-rata $N$-gain sebesar 0,72 dan dikategorikan tinggi.

\section{Pembahasan}

Berdasarkan hasil penelitian oleh peneliti bahwa LKPD berbasis discovery learning berbantuan software tracker untuk meningkatkan pemahaman konsep peserta didik kelas X di SMA Sriguna Palembang yang valid, praktis dan mampu meningkatkan kemampuan pemahaman konsep peserta didik.

Tahap evaluasi yang pertama yaitu evaluasi diri sendiri (self evaluation), dimana LKPD yang telah peneliti kembangan terlebih dahulu dievaluasi oleh peneliti bersama dosen pembimbing hingga produk siap untuk divalidasi oleh ahli/pakar. Setelah itu produk LKPD selanjutnya di evaluasi oleh expert review prototype 1 dan divalidasi oleh ahli fisika yang terdiri dari tiga validator untuk menguji kevalidan prototype 1 LKPD aspek materi, aspek bahasa dan aspek desain pembelajaran. dinyatakan sangat valid Kemudian di ujikan pada 3 (tiga) orang peserta 
Anjarwati., Lubis., Sugiarti. - Pengembangan LKPD Berbasis Discovery...

didik, hasil penilaian peserta didik tahap one to one yaitu memenuhi kategori sangat praktis. Peneliti kemudian melanjutkan kelompok kecil (small group) ,tahap ini hampir sama dengan one-to-one evaluation, bedanya peneliti menguji cobakan prototype 2 mempelajari LKPD berbasis discovery learning berbantuan software tracker kepada 10 peserta didik kelas X IPA 1 SMA Sriguna Palembang. Dengan interprestasi sangat praktis. Prototype 3 LKPD yang telah dinyatakan sangat valid dan sangat praktis kemudian diuji cobakan pada tahap field test dengan subjek penelitian berjumlah 34 peserta didik dari kelas X IPA 1 SMA Sriguna Palembang guna untuk mengetahui efek potensial LKPD terhadap pemahaman konsep peserta didik. Dengan demikian diperoleh rata-rata $\mathrm{N}$-gain peserta didik sebesar 0,72 dari nilai pretest dan posttest dengan kategori tinggi. Sebelumnya telah terdapat penelitian yang dilakukan oleh Fitriani, Hasan, \& Musri, (2016) dengan judul Pengembangan Lembar Kegiatan Peserta Didik (LKPD) Berabasis Masalah Untuk Meningkatkan
Pemahaman Konsep, diperoleh hasil dari perhitungan $N$-gain berdasarkan hasil pre-tes dan Post-test, yaitu ratarata yang diperoleh sebesar 0,61 dengan kategori sedang. Selain itu, terdapat juga penelitian yang dilakukan oleh Aprilia, Lubis, dan Lia (2020) dengan judul Pengaruh Model discovery learnig terhadap pemahaman konsep peserta didik SMA berbantuan software tracker pada materi GHS, dan diperoleh hasil bahwa terdapat pengaruh model pembelajaran discovery learning terhadap pemahaman konsep peserta didik sebesar nilai $\mathrm{t}$ hitung $=7,567$ dan $\mathrm{t}$ tabel $=1,683$.

Adapun penelitian yang relevan mengenai model pembelajaran discovery learning dilakukan oleh Nurulhidayah, Lubis, dan Ali (2020) yang mengatakan bahwa, dengan menerapkan model pembelajaran discovery learning, keaktifan serta pemahaman konsep peserta didik akan meningkat sangat baik.

Berdasarkan penelitian diatas, disimpulkan bahwa LKPD yang dikembangkan memiliki beberapa kelebihan dan kekurangan. Kelebihan dari LKPD yang dikembangkab 
Anjarwati., Lubis., Sugiarti. - Pengembangan LKPD Berbasis Discovery...

adalah disajikan gambar fenomena kehidupan sehari-hari, berbantuan software tracker dimana software tracker ini membantu peserta didik untuk mempermudah menghitung percepatan, kecepatan, dan grafik, disajikan panduan penggunaan software tracker dan disajikan panduan praktikum yang berkaitan dengan kehidupan sehari-hari. kekurangan dari LKPD ini adalah, LKPD merupakan salah satu media cetak dalam proses pembelajaran, sehingga LKPD tidak praktis untuk dibawa oleh peserta didik.

\section{KESIMPULAN DAN SARAN}

\section{Kesimpulan}

Berdasarkan hasil penelitian yang telah dilakukan maka diperoleh beberapa kesimpulan, antara lain (1) LKPD berbasis discovery learning berbantuan software tracker yang telah dikembangkan dinyatakan sangat valid ; (2) LKPD berbasis discovery learning berbantuan software tracker yang dikembangkan telah teruji kepraktisannya. Hal ini ditunjukkan dari hasil uji coba one to small group evaluation dinyatakan praktis; (3) Pembelajaran menggunakan LKPD berbasis discovery learning berbantuan software tracker memiliki efek potensial bagi subjek penelitian dengan meningkatkan kemampuan pemahaman konsep peserta didik .

\section{Saran}

Berdasarkan hasil dan pembahasan pada penelitian Pengembangan LKPD berbasis discovery learning berbantuan software tracker untuk meningkatkan pemahaman konsep peserta didik kelas X di SMA Sriguna Palembang, terdapat beberapa saran yang dapat dipertimbangkan dalam penelitian pengembangan ini diantaranya, (1) Pendidik diharapkan dapat menambah kretivitas dan wawasan terkait bahan ajar LKPD, sehingga pendidik dapat memanfaatkan bahan ajar LKPD untuk meningkatkan pemahaman konsep peserta didik; (2) Peserta didik diharapkan lebih aktif dalam mengikuti kegiatan pembelajaran dan meningkatkan pemahaman konsep; (3) Mengembangkan LKPD menggunakan aplikasi software tracker pada materi lain sesuai kebutuhan dan kondisi pembelajaran. 
Anjarwati., Lubis., Sugiarti. - Pengembangan LKPD Berbasis Discovery...

\section{DAFTAR PUSTAKA}

Hardi, A., Wahyono, U., \& Saehana, S. Pengembangan Multimedia Pembelajaran Materi Gerak Lurus Pada Permainan Tradisional Logo Berbantuan Software Tracker. JPFT (Jurnal Pendidikan Fisika Tadulako Online), 7(2).

Aprilia, M., Lubis, P. M., \& Lia, L. (2020). Pengaruh Model Discovery Learning Terhadap Pemahaman Konsep Peserta didik SMA Berbantuan Software Tracker pada Materi GHS. Jurnal Pendidikan Fisika dan Teknologi, 6(2), 320326.

Apriyani, R., Sumarni, S., \& Rukiyah, R. (2018). Pengembangan Media Pembelajaran Komik Tema Alam Semesta untuk Anak. Cakrawala Dini: Jurnal Pendidikan Anak Usia Dini, 9(2), 110-124.

Aththibby, A. R., \& Salim, M. B. (2015). Pengembangan media pembelajaran fisika berbasis animasi flash topik bahasan usaha dan energi. Jurnal Pendidikan Fisika, 3(2).

Brigenta, D., Handhika, J., \& Huriawati, F. (2017, August). Pengembangan modul berbasis discovery learning untuk meningkatkan pemahaman konsep. In Prosiding SNPF (Seminar Nasional Pendidikan Fisika) (pp. 167-173).

Badiro, D., Syuhendri, S., \& Fathurohman, A. (2019). Pengembangan media pembelajaran aplikasi android berbasis teori perubahan konseptual materi tata surya dan fase bulan mata kuliah IPBA.
Jurnal Inovasi Dan Pembelajaran Fisika, 6(1), 103-112.

Esminarto, E., Sukowati, S., Suryowati, N., \& Anam, K. (2016). Implementasi Model Stad dalam Meningkatkan Hasil Belajar Siwa. BRILIANT: Jurnal Riset dan Konseptual, 1(1), 16-23.

Firdaus, M., \& Wilujeng, I. (2018). Pengembangan LKPD inkuiri terbimbing untuk meningkatkan keterampilan berpikir kritis dan hasil belajar peserta didik. Jurnal Inovasi Pendidikan IPA, 4(1), 2640.

Fitriani, F., Hasan, M. H. M., \& Musri, M. (2016). Pengembangan Lembar Kegiatan Peserta Didik (LKPD) Berbasis Masalah untuk Meningkatkan Pemahaman Konsep dan Aktivitas Belajar Peserta Didik pada Materi Larutan Penyangga. Jurnal Pendidikan Sains Indonesia (Indonesian Journal of Science Education), 4(1).

Hasanah, U., Lesmono, A. D., \& Astutik, S. (2019). Penerapan Model Problem Based Learning Disertai Video Tracker Materi Momentum Dan Impuls Untuk Membelajarkan Kemampuan Berpikir Kritis Siswa Di SMA. Saintifika, 21(1), 71-80.

Nurulhidayah, M. R., Lubis, P. H., \& Ali, M. (2020). Pengaruh Model Pembelajaran Discovery Learning Menggunakan Media Simulasi PhET Terhadap Pemahaman Konsep Fisika Siswa. Jurnal Pendidikan Fisika, 8(1), 95-103.

Nugraha, F., Wulansari, R., Danika, I., Nurafiah, V., Lathifah, A. N., Sholihat, F. N., ... \& Kirana, K. H. 
Anjarwati., Lubis., Sugiarti. - Pengembangan LKPD Berbasis Discovery...

(2017, October). Eksperimen pesawat atwood berbasis pengolahan aplikasi tracker untuk mengamati fenomena gerak lurus beraturan dan gerak lurus berubah beraturan pada pembelajaran fisika SMA. In Prosiding Seminar Nasional Fisika (E-Journal) (Vol. 6, pp. SNF2017-EER).

Pasaribu, A., \& Saparini. (2017).

Pembangan Bahan Ajar Berbasis
Kontekstual Untuk Meremidiasi Miskonsepsi pada Materi Gaya dan Hukum Newton Tentang Gerak. Jurnal Inovasi dan Pembelajaran Fisika, 36-47.

Sugiyono. (2013). Metode Penelitian Kuantitatif, Kualitatif dan $R \& D$. Bandung: Alfabeta.

Tessmer, M.(1998). Planning and Conducting Formative Evaluations. London: Kogan Page. 